\title{
This time without 'feeling': Children's intuitive theories of art as a logical basis for learning progression in visual arts
}

\author{
Dr Karen Maras \\ UNSW Sydney \\ https://doi.org/10.37517/978-1-74286-638-3_3
}

\begin{abstract}
Dr Karen Maras is a senior lecturer in the School of Education at the University of New South Wales. As a specialist in visual arts education, she is Program Convenor, Visual Arts, Media Arts and Design Education. Prior to this appointment Karen led programs in visual arts teacher education at Australian Catholic University and also held a range of leadership roles in the ACU Faculty of Education NSW. She began her career in academia at COFA UNSW wherein she completed her undergraduate, postgraduate and doctoral studies. Karen's contributions to visual arts teacher education at UNSW Sydney and curriculum development in state and national contexts are complemented by her research on students' conceptual development, learning and curriculum issues in visual arts.
\end{abstract}

\section{Abstract}

Learning in Visual Arts has traditionally been framed as an experiential process in which feeling and intuition complement the development of aesthetic knowledge. However, while art can be about feelings and processes that develop students' expressive capacities, the complexity of art understanding and thinking extends beyond this narrow common-sense assumption. I argue that this assumption, which is represented in the Australian Curriculum: The Arts (ACARA, 2015), and even more firmly resonates in recent proposals for the revision of this curriculum (ACARA, 2021), obfuscates the conceptual and theoretical bases on which students make progress in art understanding. This paper examines the proposition that art understanding emerges progressively and can be described in conceptual terms, the basis of which can be identified in empirical research on the emergence of children's intuitive theories of art. This paper examines how selected studies articulate the cognitive grounds on which students' ontologies of art and epistemological beliefs are represented in their reasoning about art over time. It is argued that an empirically supported conception of learning anchored in students' cognitive development in art that recognises the theoretical commitments underscoring their conceptual and practical reasoning in visual arts practices $\mathrm{K}-12$ provides a logical basis for articulating progression in the subject.

\section{Introduction}

The question of how learning progression is described in Visual Arts remains a vexed issue in current curriculum developments in Australia. Ongoing debates about learning progression feature in discussions of the Australian Curriculum: The Arts F-10 (Australian Curriculum, Assessment and Reporting Authority [ACARA], 2015) (AC:TA) and the Visual Arts curriculum in New South Wales (NSW), both of which are the focus of concurrent and intertwined curriculum reviews (ACARA, 2020; New South Wales Educational Standards Authority [NESA], 2020).

The AC:TA starts from the position that process-based learning in art will yield embodied understandings of aesthetic knowledge. Through making and responding, students engage aesthetic knowledge (e.g. skills, techniques, conventions, elements, materials). Advocates of this approach argue that process-based learning provides the means for realising self-expressive ends. This 
curriculum starts from the premise that all students are intuitively pre-disposed to be aestheticians and will develop increasing sophistication through emotive enagement and aesthetic experience. By contrast, advocates for the approach taken in the NSW Visual Arts curriculum K-12 argue that process fails to make explicit the role of thinking about art and how this informs what students understand as makers and critics (Brown, 2017). The NSW curriculum starts from the position that students learn practically and conceptually through reasoning in the practices of art making, art criticism and art history (Board of Studies New South Wales, 2003). Engagement with core concepts, explanatory systems and a theory of practice support them to demonstrate increasing intellectual autonomy as they develop understandings of the relationship of conceptual knowledge and practical activities when making art or constructing critical interpretations (Maras, 2021). This conception of learning in art is grounded in empirical research focusing on the students' developing theories of art.

In this paper I argue that understanding how students intuitively understand art at different points in their development provides a basis on which progression in art learning can be described. To explore this issue of learning progression in visual arts, discussion will 1) briefly define learning progression, and 2) examine selected cross-age studies which illustrate how changes in students' intuitive theories of art change over time and provide a basis for understanding how students learn in visual arts. The paper concludes with some reflections on the terms on which research on students' intuitive theories of art provides a logical basis on which a high quality, academically rigorous curriculum F-12 can be developed.

\section{Learning progression}

Grounded in empirical studies of cognitive development, learning progression describes learning growth, placing 'explicit emphasis on ways students' thinking becomes more sophisticated over time in terms of interactions between their growing understanding of content ... and their ability to use that understanding in reasoning...' (Mosher, 2011, p. 3) in domain-specific terms. Drawing from Driver et al. (1994), the development of learning progression concerns identifying three factors; 'changes in students' ontologies within specific domains, changes in reasoning strategies, and changes in epistemological commitments', a project that involves mapping the conceptual development of younger and older students (Duschl, 2019, p. 97). As such, learning progression provides a map of iterative changes in students' understandings over time, a map that can support teachers in better anticipating the support individual students need to reach particular goals, such as curriculum standards over the duration of their learning in a specific knowledge domain (Masters, 2013). The following discussion outlines selected studies that have contributed to the stock of knowledge about conceptual development in art.

\section{Empirical research on children's conceptual development in art}

Empirical studies of students' conceptual development in art have revealed progressive changes in their ontologies of art, their reasoning and the epistemological commitments during early childhood through early adolescence. Studies of this kind focus on reasoning performances by students about the nature and function of artworks as things that exist in the world. For example, the theoretical foundations of students' intuitive theories of art have been identified (Freeman, 1995). By mapping conceptual patterns in students' general reasoning about artworks, this study identified the ontological terms on which younger and older students formulated reasons for how and why artworks exist in relation to artists, the world and beholders. Answers to questions devised to test students' thinking about these relationships revealed that younger students hold naïve realist theories of what artworks are as things in the world, equating subject matter with artwork function. 
Gradually this naïve view develops into a more sophisticated notion of artworks as representations of subject matter made by artists who draw feelings, desires and motives to do so. With the advent of intentional claims about an artwork's existence, older students progress their ideas to artworks as intentional artefacts, describing their function in the world in relation to artists as producers of art who invest artworks with intentional value in anticipation of thoughtful reception by beholders.

On these terms, students' developing ontologies of art are complemented by the development of reasoning skills when construing and justifying relationships among the concepts of artwork, beholder, subject matter and artist in which a theory of mind is demonstrated. These developments were also underscored by students' capacities to consult and apply intentional beliefs to argue how artworks were situated within intentional relationships between artworld concepts, an advance which also included a growing awareness of their own intentional agency as beholders. The conceptual and theoretical trajectory described in this example has also been confirmed by subsequent studies of students' general reasoning about art (Brown \& Freeman, 1993; Freeman \& Sanger, 1993, 1995). However, perhaps a consequence of engaging students in general conceptual reasoning, this series of studies on students' intuitive theories of artworks did not detect any evidence that children are innately orientated to aesthetic beliefs as epistemological grounds for talking about art.

Research by Maras (2010) explored in greater depth the theoretical and practical bases of children's critical reasoning in art. This study of younger and older students' critical judgements of artworks explored the terms on which they 'recognise and identify' (Wollheim, 2001) the meaning and value of examples of artworks they judged to be 'good'. While engaged in a curatorial task in which they were asked to recommend good artworks to the researcher for inclusion in an exhibition, students were invited to reason out their choices of artworks. Analysis of their reasoning revealed a great deal about changes in their understanding of art, the ontological bases on which they represent their claims about the function of artworks, and the kinds of epistemological beliefs they bring to bear in their judgements of artworks. With age, students gain greater control of their reasoning skills, mastering recursive transitions in which initial ideas are gradually renovated as they construct increasingly more complex, higher order claims about artwork meaning and value. As their dexterity in reasoning skills increases, so does the scope of the ontological bases on which they recognise artworks' properties and identify them on intentional terms. This shift represents a transition from naïve realism at the age of six to a reasonably replete account of artworks and their properties as products of artists' intentions and beliefs by the age of nine. Some students aged nine could also extend their judgements to include consideration of the role of the audience in their explanations of representational relations. Advances into intentional ontologies art are then consolidated by 12 years of age, a development confirmed by students' developing skills in consulting a range of epistemological beliefs. At this age students were well on the way to ascribing artworks' meaning and value as cultural status symbols, forms of intuitive expression and representations of style and taste. In other words, students begin to locate the function of artworks as functions of intentional transactions of the kind that occur in the art world as a social reality.

The conceptual changes identified in these two examples of empirical research on students' art understanding during the primary and early secondary years of schooling describe a pathway of understanding from ontologically naïve assumptions about how artworks exist to highly complex and robust intentional theories of art. Their intuitive assumptions about art reflect a conceptual logic and sequential consistency that is complemented by advancing skills in controlling their reasoning to represent and justify points of view. This pathway also reflects students' advance into understanding the intentional function of artworks as artefacts that are shaped by beliefs that artists adopt when producing them and that are shared among audiences of art. This trajectory in students' art understanding provides a logical basis, or a set of logical constraints on which descriptions of learning progression in visual arts can be developed (Maras, 2018). 


\section{Conclusion}

This brief account of research on students' intuitive theories of art reveals how art understanding is informed by the practicalities of building reasoned critical accounts of art that are anchored in ontological commitments and changing epistemological orientations (Driver, et al., 1994). I have argued that insight into how thinking informs skilful activity (i.e. practical and conceptual reasoning) is central to mapping students' progression in art, a factor that also supports understanding of how to teach students with a view to deepening understanding of the core concepts and principles of learning in art in time and over time (NESA, 2020).

The account of learning progression outlined in this paper places emphasis on the 'development of mind' in visual arts (Eisner, 2003). The scope of conceptual and practical reasoning as a basis for learning progression in art moves beyond intuitive processes and aesthetic knowledge to embrace a rich form of conceptual engagement in the subject that compliments the practicalities of skills, capabilities and processes in art practice (Brown, 2017). Despite pressure to 'adopt and adapt' the AC:TA in the NSW context, visual arts educators in NSW have rejected the generic framing of learning as process in AC:TA. They remain committed to retaining their current curriculum, arguing that an empirically supported conception of learning grounded in students' development in art that recognises the theoretical commitments underscoring their conceptual and practical reasoning in visual arts practice $\mathrm{K}-12$ provides a logical basis for articulating progression in the subject. This approach to establishing a basis for teaching and assessing for depth in understanding, as well as establishing a basis on which to develop progressions has already been laid in the current curriculum provisions in NSW (Maras, 2021). However, a great deal more empirical research on student's reasoning in both art making and art interpretation the middle years of schooling would support a well-rounded understanding of students' intuitive theories of art as a basis describing learning progression and for engaging in good teaching.

\section{References}

Australian Curriculum, Assessment and Reporting Authority. (2015). The Australian Curriculum: The Arts. https://www.australiancurriculum.edu.au/f-10-curriculum/the-arts/.

Australian Curriculum, Assessment and Reporting Authority. (2020). Terms of reference - review of the Australian Curriculum F-10. https://www.acara.edu.au/docs/default-source/curriculum/acreview_terms-of-reference_website.pdf.

Australian Curriculum, Assessment and Reporting Authority. (2021). The Arts Consultation Curriculum: The Australian Curriculum Review. https://www.australiancurriculum.edu.au/ consultation/the-arts/

Board of Studies New South Wales. (2003). Years 7-10 visual arts syllabus. https://www. boardofstudies.nsw.edu.au/syllabus_sc/pdf_doc/visual_arts_710_syl.pdf

Brown, N. C. M. (2017). Studies in philosophical realism in art, design and education. Springer International Publishing.

Brown, N. M., \& Freeman, N. H. (1993). Children's developing beliefs as a basis for sequencing in art education. Australian Association for Research in Education. https://www.aare.edu.au/data/ publications/1993/brown93025.pdf

Driver, R., Leach, J., Scott, P., \& Wood-Robinson, C. (1994). Young people's understanding of science concepts: Implications of cross-age studies for curriculum planning. Studies in Science Education, 24(1), 75-100. https://doi.org/10.1080/03057269408560040 
Duschl, R. A. (2019). Learning progressions: Framing and designing coherent sequences for STEM education. Disciplinary and transdisciplinary Science Education Research, 1(1), 1-10. https://doi. org/10.1186/s43031-019-0005-x

Eisner, E. W. (2003). The arts and the creation of mind. Yale University Press.

Freeman, N. H. (1995). The emergence of a framework theory of pictorial reasoning. In C. Lange-Kuttner \& G. V. Thomas (Eds.), Drawing and looking: Theoretical approaches to pictorial representation in children (pp. 135-146). Harvester Wheatsheaf.

Freeman, N. H., \& Sanger, D. (1993). Language and belief in critical thinking: Emerging explanations of pictures. Exceptionality Education Canada, 3(3), 43-58.

Freeman, N. H., \& Sanger, D. (1995). Commonsense aesthetics of rural children. Visual Arts Research, 21(2), 1-10.

Maras, K. (2010). Age-related shifts in the theoretical constraints underlying children's critical reasoning in art. Australian Art Education, 33(1), 20-28. https://search.informit.org/doi/10.3316/ informit.431497643821282

Maras, K. (2018). Mind, language and artworks as real constraints on students' critical reasoning about meaning in art. The International Journal of Art \& Design Education, 37(3), 530-540. https:// doi.org/10.1111/jade.12152

Maras, K. (2021). Ahead of its time? Reassessing what is core content in Visual Arts in the New South Wales Curriculum. Curriculum Perspectives, 1-11. https://doi.org/10.1007/s41297-02100136-6

Masters, G. (2013). Reforming education assessment: Imperatives, principles and challenges (Australian Education Review No. 57). http://research.acer.edu.au/aer/12/

Mosher, A. (2011). The role of learning progressions in standards-based education reform. CPRE Policy Briefs, RB-52. https://doi.org/10.12698/cpre.2011.rb52

New South Wales Educational Standards Authority. (2018). Terms of Reference - NSW Curriculum Review. https://nswcurriculumreform.nesa.nsw.edu.au/assets/docs/nsw-curriculum-reviewterms-of-reference.pdf

New South Wales Educational Standards Authority. (2020). Nurturing wonder and igniting passion: Designs for a new school curriculum. https://nswcurriculumreview.nesa.nsw.edu.au/home/ siteAreaContent/524abec1-f0f9-4ffd-9e01-2cc89432ad52.

Wollheim, R. (2001). On aesthetics: A review and some revisions. Literature and Aesthetics, 11, 7-32. 